AARP has a long history of supporting veterans, military, and their families, including over four million who are AARP members today. This AARP Fact Sheet provides basic data and demographic points on veterans, military and their family members in your state.

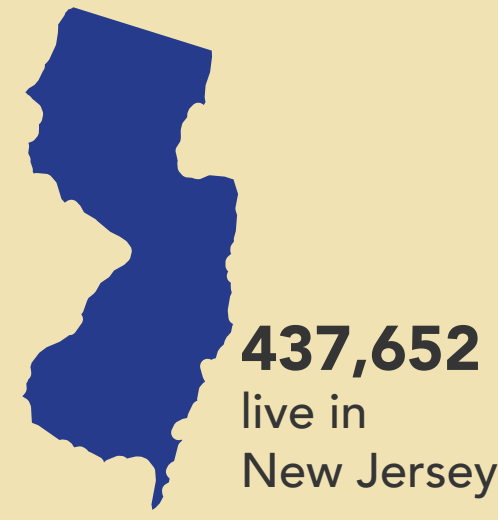

live in

New Jersey
$790 \%$ are 50 -plus

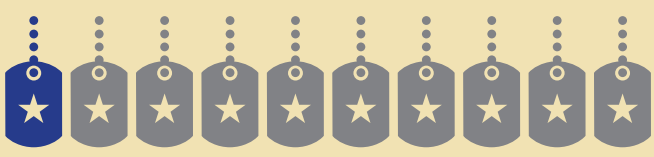

$6 \%$
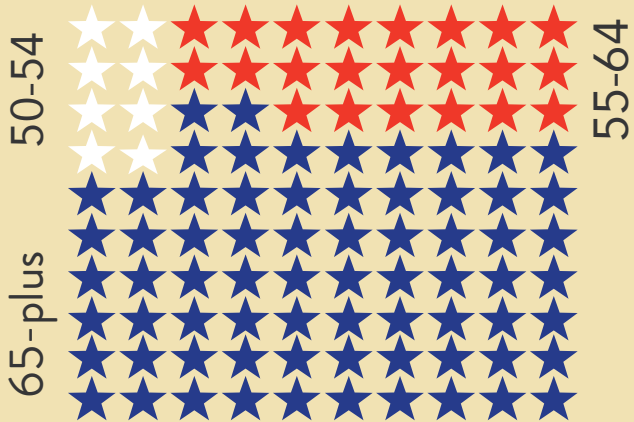

$\star 22 \% \star 70 \%$

\title{
Demographics
}

$28 \%$ have a bachelor's are enrolled in college

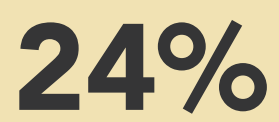

of veteran households

have children under 18

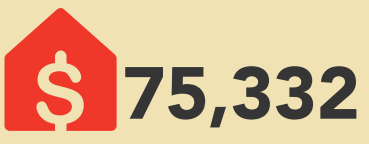

Median income
White

African American/Black $14 \%$

Hispanic $8 \%$

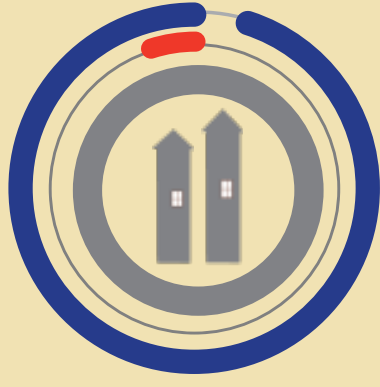

$93 \%$ live in urban areas \& $7 \%$ live in rural ones

\section{Health and Well-Being}

$12 \%$

have a service-related disability

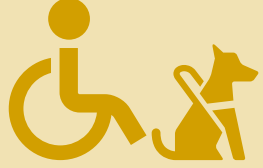

$4 \%$

are uninsured

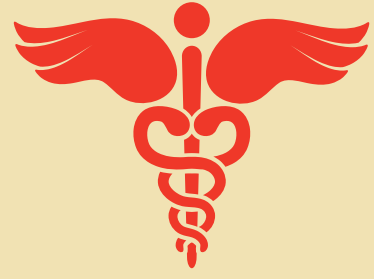

\section{$20 \%$}

have used the Veterans Administration for healthcare

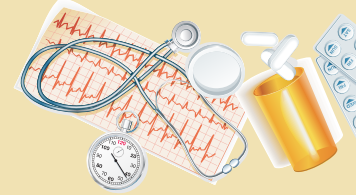

